\title{
Prevention of Cardiovascular Burden in COVID-19 Patients Suffering from Familial Hypercholesterolemia: A Global Challenge
}

\author{
Alpo Vuorio (D) - Petri T. Kovanen - Raul D. Santos · Frederick Raal
}

Received: September 26, 2021 / Published online: November 17, 2021

(c) The Author(s) 2021

\begin{abstract}
A recent meta-analysis of over 20,000 individuals showed that hospitalized COVID-19 patients with acute myocardial injury had more than fourfold higher mortality than those without such injury. Since the COVID-19 pandemic exacerbates already existing health inequalities, there is an urgent need to create measures to protect the most vulnerable patient groups, including those with a pre-existing
\end{abstract}

\footnotetext{
A. Vuorio $(\square)$

Mehiläinen, Airport Health Center, Lentäjäntie 1 E, 01530 Vantaa, Finland

e-mail: alpo.vuorio@gmail.com

A. Vuorio

Department of Forensic Medicine, University of Helsinki, Helsinki, Finland

P. T. Kovanen

Wihuri Research Institute, Helsinki, Finland

R. D. Santos

Lipid Clinic Heart Institute (Incor), University of São

Paulo, Medical School Hospital, São Paulo, Brazil

R. D. Santos

Academic Research Organization, Hospital Israelita

Albert Einstein, São Paulo, Brazil

F. Raal

Faculty of Health Sciences, University of

Witwatersrand, Johannesburg, South Africa
}

increased risk of atherosclerotic cardiovascular disease (ASCVD). A typical example is familial hypercholesterolemia (FH), a common genetic disease affecting over 30 million individuals worldwide. If left untreated or undertreated, FH patients suffer from complications of premature ASCVD, such as acute coronary syndromes, resulting in acute myocardial injury/infarction. A recent population-based analysis provided strong evidence suggesting that COVID-19 poses an even higher risk for myocardial injury in FH patients. From the long-term preventive point of view, it is important to note that, in addition to the acutely elevated risk of myocardial injury, an elevated risk of ASCVD and its complications will persist after COVID19. The decline in outpatient preventive care during the pandemic is likely to influence ASCVD risk and outcomes, particularly in highrisk patients, such as those with FH. This commentary aims to raise global awareness of the challenges that clinicians treating $\mathrm{FH}$ patients continue to face during the COVID-19 pandemic, with two low- to middle-income countries, South Africa and Brazil, serving as examples.

Keywords: Acute myocardial injury; COVID19; Endothelial dysfunction; Low-income country; Familial hypercholesterolemia; Statin; PCSK9 inhibitor; Africa; Latin America 


\section{Key Summary Points}

Hospitalized COVID-19 patients with acute myocardial injury have more than fourfold higher mortality than those without such injury.

Familial hypercholesterolemia (FH), a common genetic disease, affects over 30 million individuals worldwide, and if left untreated leads to premature atherosclerotic cardiovascular disease.

Recent population-based analysis showed that FH patients with COVID-19 are at a significantly elevated risk of acute myocardial injury.

Preventive lipid management among FH patients suffering from COVID-19 needs to be continued, or even intensified, during the infection and beyond.

\section{INTRODUCTION}

Several studies have shown that underlying cardiovascular disease is related to a poor prognosis of SARS-CoV-2 infection [1-4]. A recent meta-analysis of 20,204 patients showed that hospitalized COVID-19 patients with acute myocardial injury had more than fourfold higher mortality than COVID-19 patients without it [5]. In addition, history of coronary artery disease was an independent predictor of acute myocardial infarction (AMI) during SARSCoV-2 infection. So far, there is a lack of data regarding the impact of pre-existing cardiovascular disease on the severity of COVID-19, especially in middle-to-low- and low-income countries. The worldwide World Heart Federation Global Study on COVID-19 and Cardiovascular Disease is in progress to clarify this challenging topic [6].

Since it is now clear that the COVID-19 pandemic will exacerbate existing health inequalities, particularly in low- and middle-

income countries, there is an urgent need to create measures to protect the most vulnerable patient groups [7]. Profound health inequalities between high-to-middle- and low-income countries are highlighted by the fact that in the latter countries, only $1.6 \%$ of people had received at least one dose of COVID-19 vaccine by the end of August 2021 (https://www. ourworldindata.org/covid-vaccinations).

Indeed, the risks are exacerbated in low-income countries where the public health systems cannot respond adequately and without delay to support the protection of the most vulnerable by shielding them from infections inside and outside their homes [8].

Of concern is that during the COVID-19 pandemic, the rising number of infections limits access to healthcare even in high-income countries. Thus, the increased treatment burden causes delays in the treatment of various preexisting diseases, such as cardiometabolic diseases. The delays, again, increase the risk for complications and worsen the prognosis among such patients even without COVID-19 [9, 10].

Unfortunately, the necessary prevention and treatment strategies of COVID-19 have led to restriction measures that hamper the routine care of common chronic metabolic conditions [11]. A demonstrative example is familial hypercholesterolemia (FH), a common genetic disease with an estimated prevalence of 1 in 300 persons and affecting over 25 million individuals worldwide, which, if left untreated or undertreated, can lead to premature atherosclerotic cardiovascular disease (ASCVD), notably to different types of acute coronary syndromes with ensuing myocardial injury often already in early adulthood [12]. Unfortunately, FH is still an underdiagnosed and undertreated disease, which further aggravates the situation [13, 14]. This applies especially to the severe homozygous form of $\mathrm{FH}(\mathrm{HoFH})$, which affects about 1 in 300,000 individuals, and in which the affected individuals often develop ASCVD already in early childhood [15].

This commentary aims to raise awareness of the challenges the COVID-19 pandemic has created for clinicians with regard to cardiac health treatment of $\mathrm{FH}$ patients with COVID19, especially in Africa and Latin America. The 
impact of an acute ischemic stroke in such patients in general was the subject of a previous publication and is therefore omitted from this commentary [16]. This article is based on previously conducted studies and does not contain any new studies with human participants or animals performed by any of the authors.

\section{FH AND COVID-19 IN AFRICA}

Although it is well known that, due to a founder effect, $\mathrm{FH}$ is common in the Afrikaner, Jewish, and Indian populations of South Africa, with a prevalence as high as 1 in $80[17,18]$, there are very few studies that have reported on the prevalence of $\mathrm{FH}$ in the Black population of South Africa, let alone throughout the rest of the Africa continent. In fact, fewer than 30 cases of genetically documented FH in Black Africans have been reported since 1980 [19-21]. This shortcoming needs to be urgently addressed, as it implies that $\mathrm{FH}$ is either less prevalent than that reported on other continents worldwide or that the diagnosis of $\mathrm{FH}$ is being missed.

In South Africa, even if the prevalence of $\mathrm{FH}$ in the Black population is less than 1 in 300 , the number of cases of $\mathrm{FH}$ in this population should exceed those in the much smaller founder $\mathrm{FH}$ South African populations because Black Africans make up $90 \%$ of the total population. At an estimated prevalence of 1 in 300 persons, Africa, with a population of over 1.2 billion people, should have over 4 million FH cases. Certainly, as cardiovascular disease is the leading cause of death worldwide, many individuals and families with $\mathrm{FH}$ among Black Africans may simply be overlooked.

Elevated lipoprotein(a) $[\operatorname{Lp}(a)]$ is now a wellestablished causal risk factor for cardiovascular disease independent of low-density lipoprotein (LDL) cholesterol levels [22]. Lp(a) levels tend to be higher in African individuals. However, there have also been few reports on $\operatorname{Lp}(\mathrm{a})$ levels in African patients, and none on African individuals with FH. Hence, it remains unknown whether $\operatorname{Lp}(\mathrm{a})$ is an independent risk factor for CVD in this population group [23].

We know even less about the risk associated with COVID-19 infection or mortality from
COVID-19 in FH patients on the African continent, since no data are available. At the Johannesburg hospital lipid clinic, to date, approximately 10 genetically confirmed $\mathrm{HoFH}$ patients have had COVID-19, and fortunately they have all recovered without severe complications. However, one markedly overweight HoFH patient attending the lipid clinic in Cape Town recently died from COVID complications (personal communication, Dirk Blom). Perhaps lipid-lowering therapy, particularly high-intensity statin therapy, which is routinely prescribed for HoFH patients, has alleviated or prevented complications from COVID-19. This hope-inspiring hypothesis calls for further studies.

\section{FH AND COVID-19 IN LATIN AMERICA: BRAZIL AS AN EXAMPLE}

There is no conclusive evidence on the frequency of $\mathrm{FH}$ in Latin American (LATAM) countries. The ELSA-Brasil study suggests that heterozygous FH affects approximately 1/263 individuals in Brazil, the most populated country in LATAM [24]. Data from the IberoAmerican FH network registry indicate an elevated rate of underdiagnosis and variable frequencies of previous cardiovascular disease in LATAM (10\% in Chile, $23 \%$ in Brazil, $35 \%$ in Uruguay, $38 \%$ in Mexico, and $42 \%$ in Argentina) [25]. The frequency of cardiovascular disease (either atherosclerosis or aortic/supraaortic valvular disease) is more remarkable in patients with $\mathrm{HoFH}$, with $48 \%$ and $67 \%$ of children and adolescents, respectively, experiencing events [26]. These numbers remained extremely elevated even discounting patients from Spain and Portugal that are not in LATAM but belong to the network.

COVID-19 has strongly impacted LATAM countries, and according to the Pan American Health Organization, as of 1 May 2021, COVID19 had caused more than one million deaths in LATAM and the Caribbean regions, with almost $89 \%$ of deaths occurring in Brazil (44.3\%), Mexico (22.1\%), Colombia (8.3\%), Argentina (7.3\%), and Peru (6.7\%) (Accessed at https:// www.paho.org/en/news/21-5-2021-latinamerica-and-caribbean-surpass-1-million-covid- 
deaths, on September 22, 2021). In 2020 there was a 9\% increase in hospital deaths due to cardiovascular disease in Brazil during the pandemic, observed mainly in patients aged 20-59 years [27]. Unfortunately, it is not possible to evaluate how many of these individuals had FH. At the Heart Institute at the University of São Paulo Medical School Hospital, which runs the largest FH lipid clinic in LATAM, there was a total closure of new admittances to the lipid clinic, a full stop of the $\mathrm{FH}$ cascade screening program (Hipercol Brasil), and a severe reduction in routine consultations at the lipid clinic for $\mathrm{FH}$ and other dyslipidemia patients during 2020. However, the hospital used teleconference and pharmacy resources to keep FH patients taking their lipid-lowering medications. Services were reinstated in 2021, and the cascade screening program still runs with restrictions. Unfortunately, there is no reliable evidence in the literature about how COVID-19 has affected individuals with $\mathrm{FH}$ and their healthcare in other LATAM countries. Therefore, the overall impact for the region remains to be determined.

\section{MECHANISTIC INSIGHTS AND CONCLUSIONS}

Several comorbidities affecting the cardiovascular system, including FH with lifelong preexisting endothelial dysfunction and premature ASCVD, predispose COVID-19 patients to acute cardiac complications already in middle age [28]. This view is supported by a recent population-based analysis which showed that $\mathrm{FH}$ patients with COVID-19 are at a significantly elevated risk of AMI [29]. Regarding the mechanisms of cardiac injury in COVID-19 patients in general, the endothelial cells of the myocardial microvessels in particular, rather than those of the epicardial coronary arteries, show high ACE2 expression and are sensitive to SARS-CoV2 infection and the resulting thrombotic microangiopathy [30-32]. Moreover, the cardiomyocytes may become infected by the virus (myocarditis) and so add to the cardiac injury. In addition to the direct SARS-CoV-2 infection (endotheliitis), endothelial cells are also damaged by the uncontrolled innate inflammatory response (cytokine storm) and the dysregulated local and systemic immune responses triggered by the viral infection of the host.

In $\mathrm{FH}$ patients, the severe hypercholesterolemia renders the endothelium of epicardial coronary arteries dysfunctional in childhood, and the inflammatory atherosclerotic lesions which develop already in early adulthood in the coronary arteries then further dysfunctionally activate the lesion-covering endothelium [14]. Therefore, we can infer that in FH patients with COVID-19, the pre-existing severe endothelial dysfunction in the atherosclerotic coronary arteries (even with low ACE2 expression) is likely to be highly sensitive to the additional direct and indirect virus-dependent damages which then contribute to an increased risk of AMI observed in these patients [29]. Taken together, a pre-existing endothelial dysfunction associated with any cardiometabolic comorbidity sensitizes the cardiovascular system to further injury when the patient develops COVID19 [1], FH representing prime example of a comorbidity that predicts poorer clinical outcome in patients with COVID-19 [29, 33].

From the preventive point of view, it is important to note that, in addition to the acutely elevated risk of myocardial injury in patients with COVID-19, an elevated risk of ASCVD and its clinical complications may continue after COVID-19 [29]. Such sustained increased risk of ASCVD has been previously related to other coronavirus infections (MERS$\mathrm{CoV}$ and SARS-CoV) in non-FH patients [34] and to Chlamydia pneumoniae infection in $\mathrm{FH}$ patients [35]. A very recent self-controlled case series and matched cohort study of 86,742 Swedish COVID-19 patients showed that SARSCoV-2 infection is a significant risk factor for AMI up to 4 weeks following the infection [36]. The authors also raised concerns related to the long-term effects of the burden of morbidity and mortality related to cardiovascular health, especially in low-income developing regions of the world. It is thus justified to remind clinicians that preventive lipid treatment among $\mathrm{FH}$ patients with COVID-19 needs to be continued or even intensified after the acute illness $[14,37,38]$. In COVID-19 patients, in general, 
significant benefits of the use of statins have been shown in terms of cardiovascular risk reduction [39-41]. Additionally, pharmacological PCSK9 inhibition can be considered in hospitalized FH patients with COVID-19 [42]. In such FH patients with lifelong pre-existing endothelial dysfunction, combining an efficient cholesterol-lowering regimen with antithrombotic medications is prudent, when attempting to prevent the often-lethal thrombotic complications of the SARS-CoV-2 infection [43].

\section{ACKNOWLEDGEMENTS}

Funding. Dr. Santos is a recipient of a scholarship from the Conselho Nacional de Pesquisa e Desenvolvimento Tecnologico (CNPq) process \# 303734/2018-3, Brazil. No rapid service fee was received by the journal for the publication of this article.

Disclosures. Alpo Vuorio has nothing to disclose. Petri Kovanen has received consultancy fees, lecture honoraria, and/or travel fees from Amgen, Novartis, Raisio Group, and Sanofi. Raul Santos has received honoraria related to consulting, research, and/or speaker activities from Abbott, Amgen, Aché, Astra Zeneca, EMS Esperion, GETZ Pharma, Hypera, Kowa, Libbs, Merck, MSD, Novo-Nordisk, Novartis, PTC Therapeutics, Pfizer, and Sanofi. Frederick Raal has received research grants, honoraria, or consulting fees for professional input and/or lectures from Sanofi, Regeneron, Amgen, and Novartis.

Authorship. All named authors meet the International Committee of Medical Journal Editors (ICMJE) criteria for authorship for this article, take responsibility for the integrity of the work as a whole, and have given their approval for this version to be published. All the authors of this paper have contributed equally to the work and preparation of the manuscript.

Authorship Contributions. All authors listed have made a substantial, direct, and intellectual contribution to the work, and approved it for publication.

Compliance with Ethics Guidelines. This article is based on previously conducted studies and does not contain any new studies with human participants or animals performed by any of the authors.

Data Availability. Data sharing is not applicable to this article as no datasets were generated or analyzed during the current study.

Open Access. This article is licensed under a Creative Commons Attribution-NonCommercial 4.0 International License, which permits any non-commercial use, sharing, adaptation, distribution and reproduction in any medium or format, as long as you give appropriate credit to the original author(s) and the source, provide a link to the Creative Commons licence, and indicate if changes were made. The images or other third party material in this article are included in the article's Creative Commons licence, unless indicated otherwise in a credit line to the material. If material is not included in the article's Creative Commons licence and your intended use is not permitted by statutory regulation or exceeds the permitted use, you will need to obtain permission directly from the copyright holder. To view a copy of this licence, visit http://creativecommons.org/licenses/bync/4.0/.

\section{REFERENCES}

1. Bansal M. Cardiovascular disease and COVID-19. Diabetes Metab Syndr. 2020;14:247-50.

2. Liu PP, Blet A, Smyth D, Li H. The science underlying COVID-19: Implications for the cardiovascular system. Circulation. 2020;142:68-78.

3. Tian W, Jiang W, Yao J, et al. Predictors of mortality in hospitalized COVID-19 patients: a systematic review and meta-analysis. J Med Virol. 2020;92: $1875-83$.

4. Chilazi M, Duffy EY, Thakkar A, Michos ED. COVID and cardiovascular disease: what we know in 2021. Curr Atheroscler Rep. 2021;23:37. 
5. Abate SM, Mantefardo B, Nega S, et al. Global burden of acute myocardial injury associated with COVID-19: a systematic review, meta-analysis, and meta-regression. Ann Med Surg. 2021;68:102594.

6. Sliwa K, Singh K, Raspail L, et al. The World Heart Federation Global Study on COVID-19 and cardiovascular disease. Glob Heart. 2021;16:22.

7. Mason KE, Maudsley G, McHale P, et al. Age-adjusted associations between comorbidity and outcomes of COVID-19: a review of the evidence from the early stages of the pandemic. Front Public Health. 2021;9:584182.

8. Dahab M, van Zandvoort K, Flasche S, et al. COVID19 control in low-income settings and displaced populations: what can realistically be done? Confl Health. 2020;14:54.

9. Rubino F, Amiel SA, Zimmet P, et al. New-onset diabetes in covid-19. N Engl J Med. 2020;383: 789-90.

10. le Roux CW. COVID-19 alters thinking and management in metabolic diseases. Nat Rev Endocrinol. 2021;17:71-2.

11. Hill MA, Sowers JR, Mantzoros CS. Commentary: COVID-19 and obesity pandemics converge into a syndemic requiring urgent and multidisciplinary action. Metabolism. 2021;114:154408.

12. Representatives of the Global Familial Hypercholesterolemia Community, Wilemon KA, Patel J, et al. Reducing the clinical and public health burden of familial hypercholesterolemia: a global call to action. JAMA Cardiol. 2020;5:217-29.

13. Stock J. First insights from the EAS familial hypercholesterolaemia collaboration registry: $\mathrm{FH}$ is still underdiagnosed and undertreated. Atherosclerosis. 2019;290:138-9.

14. Vuorio A, Raal F, Kaste M, Kovanen PT. Familial hypercholesterolaemia and COVID-19: a two-hit scenario for endothelial dysfunction amenable to treatment. Atherosclerosis. 2021;320:53-60.

15. Raal FJ, Santos RD. Homozygous familial hypercholesterolemia: current perspectives on diagnosis and treatment. Atherosclerosis. 2012;223:262-8.

16. Vuorio A, Kaste M, Kovanen PT. Familial hypercholesterolemia and statins in the COVID-19 era: mitigating the risk of ischemic stroke. eNeurologicalSci. 2021;23:100344.

17. Rubinsztein DC, van der Westhuyzen DR, Coetzee GA. Monogenic primary hypercholesterolaemia in South Africa. S Afr Med J. 1994;84:339-44.
18. Smyth N, Ramsay M, Raal FJ. Population specific genetic heterogeneity of familial hypercholesterolemia in South Africa. Curr Opin Lipidol. 2018;29:72-9.

19. Van Wingerden N. Primary familial hypercholesterolaemia in a South African black. S Afr Med J. 1981;60:554-6.

20. Marais AD, Berger GMB. A diversity of genetic hyperlipoproteinaemias in black patients. S Afr Med J. 1986;70:583-7.

21. Ibe UK, Whittall R, Humphries SE, Pilcher GJ, Raal FJ. Analysis of mutations causing familial hypercholesterolaemia in black South African patients of different ancestry. S Afr Med J. 2017;107:145-8.

22. Nordestgaard BG, Chapman MJ, Ray K, et al. Lipoprotein(a) as a cardiovascular risk factor: current status. Eur Heart J. 2010;31:2844-53.

23. Pare G, Caku A, McQuuen M, et al. Lipoprotein(a) levels and the risk of myocardial infarction among 7 ethnic groups. Circulation. 2019;139: 1472-82.

24. Harada PH, Miname MH, Benseñor IM, Santos RD, Lotufo PA. Familial hypercholesterolemia prevalence in an admixed racial society: sex and race matter. The ELSA-Brasil. Atherosclerosis. 2018;277: 273-7.

25. Santos RD, Bourbon M, Alonso R, et al. Clinical and molecular aspects of familial hypercholesterolemia in Ibero-American countries. J Clin Lipidol. 2017;11:160-6.

26. Alves AC, Alonso R, Diaz-Diaz JL, et al. Phenotypical, clinical, and molecular aspects of adults and children with homozygous familial hypercholesterolemia in Iberoamerica. Arterioscler Thromb Vasc Biol. 2020;40:2508-15.

27. Normando PG, Arimatéia Araujo-Filho J, de Alcântara FG, et al. Reduction in hospitalization and increase in mortality due to cardiovascular diseases during the COVID-19 pandemic in Brazil. Arq Bras Cardiol. 2021;116:371-80.

28. Mansueto G, Niola M, Napoli C. Can COVID 2019 induce a specific cardiovascular damage or it exacerbates pre-existing cardiovascular diseases? Pathol Res Pract. 2020;216:153086.

29. Myers KD, Wilemon K, McGowan MP, et al. COVID-19 associated risks of myocardial infarction in persons with familial hypercholesterolemia with or without ASCVD. Am J Prev Cardiol. 2021;7: 100197. 
30. Del Turco S, Vianello A, Ragusa R, Caselli C, Basta G. COVID-19 and cardiovascular consequences: is the endothelial dysfunction the hardest challenge? Thromb Res. 2020;196:143-51.

31. Maccio U, Zinkernagel AS, Shambat SM, et al. SARSCoV-2 leads to a small vessel endotheliitis in the heart. EBioMedicine. 2021;63:103182.

32. Varga Z, Flammer AJ, Steiger P, et al. Endothelial cell infection and endotheliitis in COVID-19. Lancet. 2020;395:1417-8.

33. Vuorio A, Watts GF, Kovanen PT. Familial hypercholesterolaemia and COVID-19: triggering of increased sustained cardiovascular risk. J Intern Med. 2020;287:746-7.

34. Liu Y, Wu S, Qin M, Jiang W, Liu X. Prevalence of cardiovascular comorbidities in coronavirus disease 2019, Severe Acute Respiratory Syndrome, and Middle East Respiratory Syndrome: Pooled analysis of published data. J Am Heart Assoc. 2020;9: $\mathrm{e} 016812$.

35. Kontula K, Vuorio A, Turtola H, Saikku P. Association of seropositivity for Chlamydia pneumoniae and coronary artery disease in heterozygous familial hypercholesterolaemia. Lancet. 1999;354:46-7.

36. Katsoularis I, Fonseca-Rodríguez O, Farrington $\mathrm{P}$, Lindmark K, Fors Connolly AM. Risk of acute myocardial infarction and ischaemic stroke following COVID-19 in Sweden: a self-controlled case series and matched cohort study. Lancet. 2021;398: 599-607.
37. Kovanen PT, Raal F, Vuorio A. Patients with familial hypercholesterolemia and COVID-19: efficient and ongoing cholesterol lowering is paramount for the prevention of acute myocardial infarction. Am J Prev Cardiol. 2021;7:100224.

38. Vuorio A, Strandberg TE, Raal F, Santos R, Kovanen PT. Familial hypercholesterolemia and COVID-19: a menacing but treatable vasculopathic condition. Atheroscler Plus. 2021;43:3-6.

39. Chow R, Im J, Chiu N, et al. The protective association between statins use and adverse outcomes among COVID-19 patients: a systematic review and meta-analysis. PLoS ONE. 2021;16:e0253576.

40. Talasaz AH, Sadeghipour P, Aghakouchakzadeh M, et al. Investigating lipid-modulating agents for prevention or treatment of COVID-19: JACC stateof-the-art review. J Am Coll Cardiol. 2021;78: $1635-54$.

41. Wu KS, Lin PC, Chen YS, Pan TC, Tang PL. The use of statins was associated with reduced COVID-19 mortality: a systematic review and meta-analysis. Ann Med. 2021;53:874-84.

42. Vuorio A, Kovanen PT. PCSK9 inhibitors for COVID-19: an opportunity to enhance the antiviral action of interferon in patients with hypercholesterolaemia. J Intern Med. 2021;289:749-51.

43. Vuorio A, Lassila R, Kovanen PT. Hypercholesterolemia and COVID-19: statins for lowering the risk of venous thromboembolism. Front Cardiovasc Med. 2021;8:711923. 